\title{
Pravastatin Use and Risk of Coronary Events and Cerebral Infarction in Japanese Men with Moderate Hypercholesterolemia : The Kyushu Lipid Intervention Study
}

\author{
The Kyushu Lipid Intervention Study Group
}

Members of the Study Group are listed in the Appendix.

\begin{abstract}
The Kyushu Lipid Intervention Study (KLIS) aimed to investigate the effects of pravastatin in the primary prevention of coronary events and cerebral infarction in Japanese men aged 4574 years with serum total cholesterol of $\geq 220 \mathrm{mg} / \mathrm{dl}(5.69 \mathrm{mmol} / \mathrm{l})$. The coronary events included myocardial infarction, coronary artery surgery and angioplasty, cardiac death, and sudden death. A total of 5,640 patients were recruited, and 3,061 and 2,579 were allocated to the pravastatin (10-20 mg/day) and conventional treatment, respectively. They were followed up for 5 years on average. Due to unsuccessful randomization, a protocol-based analysis was carried out with adjustment for coronary risk factors at baseline using the Cox proportional hazards model. For several reasons (serum total cholesterol of $\geq \mathbf{3 0 0} \mathrm{mg} / \mathrm{dl}$, use of drugs excluded in protocol, etc.), 2,219 men in the pravastain group and 1,634 in the conventional treatment group were used in the analysis. The baseline total cholesterol levels were $254 \mathrm{mg} / \mathrm{dl}$ in the pravastain group and $243 \mathrm{mg} / \mathrm{dl}$ in the conventional treatment group. Serum total cholesterol levels fell by $15 \%$ in the pravastain group and by $8 \%$ with the conventional treatment group. Adjusted relative risks for pravastatin versus conventional treatment were : coronary events 0.86 (one-side $p=0.23)$, cerebral infarction $0.78(p=$ $0.13)$, and the two outcomes combined $0.81(p=0.08)$. These findings add to evidence that pravastatin use is beneficial in the prevention of coronary events and cerebral infarction in hypercholesterolemic Japanese patients, and suggest that pravastatin may be more protective against cerebral infarction. J Atheroscler Thromb, 2000; $7: 110-121$.
\end{abstract}

Key words: Primary prevention, Myocardial infarction, Coronary artery disease, Protocolbased analysis

\section{Introduction}

A large body of epidemiological studies have shown that elevated levels of serum total cholesterol and more specifically low density lipoprotein (LDL) cholesterol are an independent, major risk factor for coronary artery disease (CAD) (1-3). A positive association between

Address for correspondence: Jun Sasaki, MD, The Second Department of Internal Medicine, Fukuoka University School of Medicine, 7-45-1 Nanakuma, Jonan-ku, Fukuoka 8140180, Japan.

Tel: +81-92-801-1011, Fax: +81-92-862-7601

E-mail: jsasaki@cis.fukuoka-u.ac.jp

Received February 9, 2000

Accepted for publication May 12, 2000. serum total cholesterol and CAD has been observed even in Japanese and Chinese populations who have relatively low levels of serum total cholesterol $(4,5)$. Earlier primary prevention trials have shown that lowering blood cholesterol levels to a reduction in coronary events among hypercholesterolemic patients (6-9), but raised concerns on possible adverse effects of the long-term use of lipid -lowering drugs in particular as regards cancer risk and external deaths $(6,7,10,11)$. The advent of HMG-CoA reductase inhibitors, which have a potent cholesterollowering effect $(12,13)$, have naturally prompted many types of clinical trials. The use of stains has been shown to alleviate atherosclerotic lesions in the coronary and carotid arteries (14-16), to prevent first and recurrent coronary events (17-19), and to reduce CAD-related 
mortality (17-20). Some of these trials have also demonstrated that statins prevent the occurrence of stroke in patients with CAD $(19,21)$. These beneficial effects of statins, however, have been documented exclusively in Western populations. It remains uncertain whether the use of statins for hypercholesterolemia is as beneficial in Japanese as in the Western populations. Japan is uniquely different from Western countries in that CAD -related mortality is lower and stroke mortality is higher $(22,23)$. The only a small trial of Japanese patients with CAD showed that pravastatin inhibited the progression of coronary atherosclerosis (24).

While several large-scale clinical trials were under way $(25,26)$, the Kyushu Lipid Intervention Study (KLIS) was initiated investigate the effect of pravastatin, as compared with conventional hypolipidemic treatment, in the primary prevention of not only coronary events but also cerebral infarctin in Japanese men with serum total cholesterol levels of $220 \mathrm{mg} / \mathrm{dl}$ or greater (27). Although the KLIS was intended to be a randomized trial, random allocation to the two treatments was not successfully carried out. However, because no large-scale trial had ever been reported in Japan, the KLIS was continued as a nonrandomized trial with an average 5-year observation (27). This paper describes the overall effects of pravastatin on the occurrence of major coronary events, cerebral infarction, and total mortality. The paper also presents the results from a compliance-based analysis.

\section{Methods}

Details of the study design, patient recruitment, and baseline data have been described previously (27). The executive committee designed the study and directed various activities in conducting the study. The trial office was responsible for general study coordination and the conduct of the trial. The trial office recruited study physicians with the help of local study organizers throughout the Kyushu District. The study was designed in accordance with the Helsinki declaration on medical research, and was approved by the ethical committee at the principal investigator's affiliated institution.

\section{Design and patients}

The study intended to allocate approximately 6,000 male patients aged $45-74$ years with primary hypercholesterolemia defined as $220 \mathrm{mg} / \mathrm{dl}(5.69 \mathrm{mmol} / \mathrm{l})$ or greater to either pravastatin or conventional treatment, and to follow up them for five years on average. The required sample size was estimated to be approximately 3,000 in each group to detect a $30 \%$ decrease in the coronary events combined in the pravastatin group with a $5 \%$ significance level (one-sided) and $80 \%$ power. It was assumed that the combined incidence rate of coronary events in the cohort would be $3.5 \%$ for 5 years without any treatment based on several assumptions (27). The reduction of the combined coronary endpoints was expected to be at most $10 \%$ in the conventional treatment group, and a $45 \%$ reduction in coronary events was assumed in the pravastatin group. A $20 \%$ drop-out rate over five years was assumed in both treatment groups (28).

Eligible patients were men aged 45-74 years with serum total cholesterol of $\geq 220 \mathrm{mg} / \mathrm{dl}(5.69 \mathrm{mmol} / \mathrm{l})$ at least two measurements in the pretreatment period. The definition of hypercholesterolemia was in accordance with the guidelines of the Japan Atherosclerosis Association (29). The eligibility criteria excluded patients with the following conditions : serum HDL cholesterol of $\geq 80 \mathrm{mg} /$ dl $(2.07 \mathrm{mmol} / \mathrm{l})$; a history of myocardial infarction, coronary bypass surgery, coronary angioplasty, cerebral hemorrhage or infarction; congenital or rheumatic heart disease; significantly life-limiting conditions such as renal failure and liver disease; drug sensitivity ; and secondary hyperlipidemia such as nephrotic syndrome, hypothyroidism, and steroid use.

Each study physician recruited eligible patients from among patients at his/her clinics or hospital. Each eligible patient was informed of the study purpose, medication methods, possible beneficial and adverse effects, and voluntary withdrawal from the study. Potential participants not under medication for hyperlipidemia were observed for at least 2 weeks, and patients on hypolipidemic drugs were observed for at least 4 weeks after discontinuation of the lipid-lowering drugs.

\section{Allocation and treatment}

A set of sealed envelopes was prepared so that the patients could be randomly and equally allocated to either pravastatin or conventional treatment. A set or sets of sealed envelopes were distributed to each study physician with an instruction that the envelopes be opened in numerical order after confirmation of eligibility of patients and their voluntary participation. Pravastatin was prescribed at a dosage of $10-20 \mathrm{mg}$ per day, an officially approved dose in Japan. The conventional treatment included medication with hypolipidemic drugs other than probucol, bezafibrate, and statins as well as dietary and/ or exercise therapy.

\section{Laboratory measurements and baseline survey}

Serum total cholesterol, HDL cholesterol, triglycerides, and other clinical and biochemical variables were determined at baseline and subsequently in the follow-up. Serum levels of LDL cholesterol were calculated using the Friedewald method for patients with serum triglycerides of $<400 \mathrm{mg} / \mathrm{dl}(30)$. Also recorded at the baseline survey were prior use of hypolipidemic drugs, current medication, concurrent diseases, smoking habit, and alcohol drinking. Laboratory measurements were done at different laboratories, but each study physician was requested to use the same laboratory throughout the study period.

Hypertension was defined as present if a patient had 
either systolic blood pressure of $\geq 160 \mathrm{mmHg}$ and/or diastolic blood pressure of $\geq 95 \mathrm{mmHg}$ or if he was under medication for hypertension. Subjects were defined as having diabetes mellitus if they had either fasting plasma glucose of $\geq 140 \mathrm{mg} / \mathrm{dl}$ or hemoglobin A1c of $\geq 6.5 \%$ or if they were under medication for diabetes mellitus. The presence of angina pectoris was based on the study physician's diagnosis. Daily alcohol use was defined as drinking alcohol on 5 days or more frequently per week.

\section{Endpoint definition and ascertainment}

The primary endpoints were fatal and nonfatal myocardial infarction, coronary artery surgery and angioplasty, cardiac death, and sudden and unexpected death. The diagnostic criteria of these events were essentially the same as those used in the Lipid Research Clinics Trial (31), and have been described previously (27). Only definite cases of the coronary events were used in the present study. The combined incidence of these coronary events was a primary outcome of the study. Outcomes of secondary interest were cerebral infarction and total mortality. Both definite and suspected cerebral infarction were used in the present study. Definite diagnosis of cerebral infarction was made when typical symptoms and signs were accompanied by diagnostic findings in either computerized tomography or magnetic resonance imaging or cerebral angiography; diagnosis based only on clinical signs and symptoms was regarded as a suspected case. The cardiovascular endpoint and adverse effect committee regularly reviewed all possible cases of the primary and secondary endpoints on the basis of the abstracts of medical records prepared by the study physicians, laboratory data, and, if available, serial electrocardiograms. An underlying cause of death was classified and coded in accordance with the 9th revision of the International Disease Classification, based on a death certificate and/or a reported abstract of the medical record. Each patient was under the medical care of a study physician. The study physicians were requested to report promptly the cardiovascular endpoints and deaths to the trial office. Periodic follow-up forms were sent to each physician at 3,6, and 12 months after the beginning of treatment, and annually thereafter for the purpose of ascertaining the primary and secondary endpoints and obtaining clinical and laboratory data on adverse effects. When an endpoint outcome was reported, an additional survey form was sent to each physician to collect detailed clinical data.

\section{Conduct of the study}

During the period from May 1990 to September 1993, a total of 5,640 patients were enrolled by 902 physicians, and 3,061 and 2,579 men each were allocated to the pravastatin and conventional treatment, respectively. As seen from the unequal numbers of patients in the two groups, randomization was not successful. Patients having coronary risk factors were more frequent in the prevastatin group, and the control group included disproportionately fewer patients with severe hypercholesterolemia. In the progress of the study, the Ministry of Health and Welfare enforced a new regulation for clinical trials, requiring a written agreement of contract between a participating hospital/clinic, not an individual physician, and a sponsoring pharmaceutical company. As a result of this regulation, many participating physicians had to withdraw from the study (see below).

From January to May in 1998, an endpoint survey was carried out to make a full ascertainment of coronary events, incidence of cerebral infarction, cerebral hemorrhage, cancer incidence, and deaths from all causes until the end of 1997. Each study physician also reconfirmed the summary information regarding drug prescription to individual patients and their compliance, which was prepared by the trial office based on the returned follow-up forms. Study physicians made direct contact with patients who had ceased to visit the physicians by telephone and mail.

\section{Statistical analysis}

As the KLIS was an observational study, a protocolbased analysis was employed with adjustment for coronary risk factors at baseline. Because patients with serum total cholesterol of $\geq 300 \mathrm{mg} / \mathrm{dl}$ were extremely few in the conventional treatment group, such patients were excluded to secure comparability between the two groups. The analysis excluded patients for whom the drugs excluded in protocol were prescribed prior to the occurrence of coronary events or cerebral infarction and those with missing values for covariates. The numbers of men excluded in the pravastatin and control groups according to specific reasons were as follows; voluntary withdrawal 98 and 49 ; no contract with participating hospitals or clinics 247 and 369 ; later discovery of ineligibility 52 and 45 (mostly having a history of endpoint diseases) ; baseline serum total cholesterol $\geq 300 \mathrm{mg} / \mathrm{dL}$ 178 and 34 ; use of the drugs excluded in protocol 131 and 351 ; and missing covariates 136 and 97 . Thus 2,219 men in the pravastatin group and 1,634 in the conventional treatment group remained in the main analysis.

Compliance was assessed in the pravastatin group allowing for both a duration of prescription and a physician's rating of drug intake on average for each year; compliance in the control group was not considered because non-pharmacological treatment was used in part of the control group. Drug intake was assessed by using 4 precoded categories: "having taken as prescribed"; "occasionally missed the drug"; "having left half or more of the prescribed dose"; and "having hardly taken". Arbitrary coefficients of $1.0,0.7,0.4$, and 0.1 were assigned to the four levels of drug intake in order. The compliance score was calculated by dividing the sum of the products of the prescription period and intake coefficient for each 
Table 1. Summary of baseline characteristics of patients.

\begin{tabular}{|c|c|c|c|}
\hline Variable & $\begin{array}{l}\text { Pravastatin } \\
(n=2,219)\end{array}$ & $\begin{array}{c}\text { Conventional } \\
\text { treatment } \\
(n=1,634)\end{array}$ & $\begin{array}{c}p \text {-value* } \\
\text { for difference }\end{array}$ \\
\hline Age (year) & $58.0(8.0)$ & $58.0(8.2)$ & 0.99 \\
\hline Body mass index $\left(\mathrm{kg} / \mathrm{m}^{2}\right)$ & $24.1(2.8)$ & $23.9(2.8)$ & 0.01 \\
\hline Total cholesterol (mg/dl) & $254.1(18.7)$ & $242.8(16.0)$ & $<0.001$ \\
\hline LDL cholesterol $(\mathrm{mg} / \mathrm{dl})^{\dagger}$ & $169.1(23.2)$ & $159.9(20.6)$ & $<0.001$ \\
\hline HDL cholesterol (mg/dl) & $48.9(12.0)$ & $49.7(11.9)$ & 0.04 \\
\hline Triglycerides $(\mathrm{mg} / \mathrm{dl})^{\ddagger}$ & $\begin{array}{c}173.6 \\
(120-238)^{\S}\end{array}$ & $\begin{array}{c}156.0 \\
(109-217)^{\S}\end{array}$ & $<0.001$ \\
\hline Angina pectoris $(\%)$ & 10.6 & 8.2 & 0.01 \\
\hline Hypertension (\%) & 44.1 & 42.0 & 0.21 \\
\hline Diabetes mellitus (\%) & 21.8 & 24.4 & 0.06 \\
\hline Use of lipid-lowering drugs (\%) & 13.6 & 7.2 & $<0.001$ \\
\hline Current smoking (\%) & 37.6 & 40.8 & 0.04 \\
\hline Daily alcohol use (\%) & 39.2 & 42.1 & 0.07 \\
\hline
\end{tabular}

Values are means and standard deviation in parentheses unless otherwise specified. *Based on Wilcoxon test or chi-square test (for dichotomous variables).

†Numbers of men were 2,079 in the pravastatin group and 1,558 in the control group.

${ }^{\ddagger}$ Numbers of men were 2,217 in the pravastatin group and 1,631 in the control group.

${ }^{\S}$ Geometric mean and inter-quartile range in parentheses.

Table 2. Person-years at risk and numbers of men unknown of the occurrence of different endpoints until the end of 1997 in the pravastatin and conventional treatment groups.

\begin{tabular}{|c|c|c|c|c|}
\hline \multirow{2}{*}{ Event } & \multicolumn{2}{|c|}{ Person-years at risk } & \multicolumn{2}{|c|}{$\begin{array}{l}\text { No. of men with unknown status } \\
\text { of the event }\end{array}$} \\
\hline & Pravastatin & Control* & Pravastatin & Control* \\
\hline Coronary events & 11,280 & 7,914 & $53(2.4)$ & $44(2.7)$ \\
\hline Cerebral infarction & 11,333 & 7,938 & $52(2.3)$ & $45(2.8)$ \\
\hline Coronary events and & 11,197 & 7,831 & $51(2.3)$ & $44(2.7)$ \\
\hline Total mortality & 11,485 & 8,092 & $24(1.1)$ & $16(1.0)$ \\
\hline
\end{tabular}

In parentheses are percentages.

*Conventional treatment.

'The earlier event was counted in the case of concurrent occurrences.

year by the total observation period. Compliance was classified as good if the score was $\geq 0.75$, and otherwise as poor.

Age-adjusted rates were calculated by the direct method using the whole person-years stratified by a 5year age class as standard. The Cox proportional hazards model was used to adjust for the covariates as well as to allow for censorship in the follow-up. Statistical adjustment was made for age (5-year class), serum total cholesterol, serum HDL cholesterol, body mass index, angina pectoris, hypertension, diabetes mellitus, prior use of lipid-lowering drugs, current smoking, and daily alcohol use. Total cholesterol, HDL cholesterol, and body mass index were each categorized at the quartiles in the distribution of men in both groups combined, and dichotomous variables were used for the other covariates. Indicator variables were created to represent the categories of each covariate. Adjusted relative risk and $90 \%$ or $95 \%$ confidence interval $(\mathrm{Cl})$ were obtained from a regression coefficient and standard error for the corresponding indicator variable. One-sided $p$-values were used for primary and secondary endpoints because we a priori expected protective effects of pravastatin use, and otherwise two-sided $p$-values were used; $p$-values $<0.05$ were regarded as statistically significant. All statistical computations were done by the SAS software version 6.12 (SAS Institute, Inc., Carry, NC). Two interim analyses were done using the data of 2.5 and 3.5 years each on average in the follow-up.

\section{Results}

\section{Baseline characteristics}

Table 1 compares the baseline characteristics of 2,219 men in the pravastatin group and 1,634 men in the conventional treatment group using two-sided $p$-values. Serum total cholesterol concentrations were measured twice for 957 men (43.1\%) in the pravastatin group and 754 men $(46.1 \%)$ in the conventional treatment group. For these patients, the average of the two values was taken as a baseline concentration. Although men with serum total cholesterol levels of $\geq 300 \mathrm{mg} / \mathrm{dl}$ were excluded, the mean concentration of serum total cholesterol was $11 \mathrm{mg} /$ $\mathrm{dl}$ higher in the pravastatin group than in the conventional 

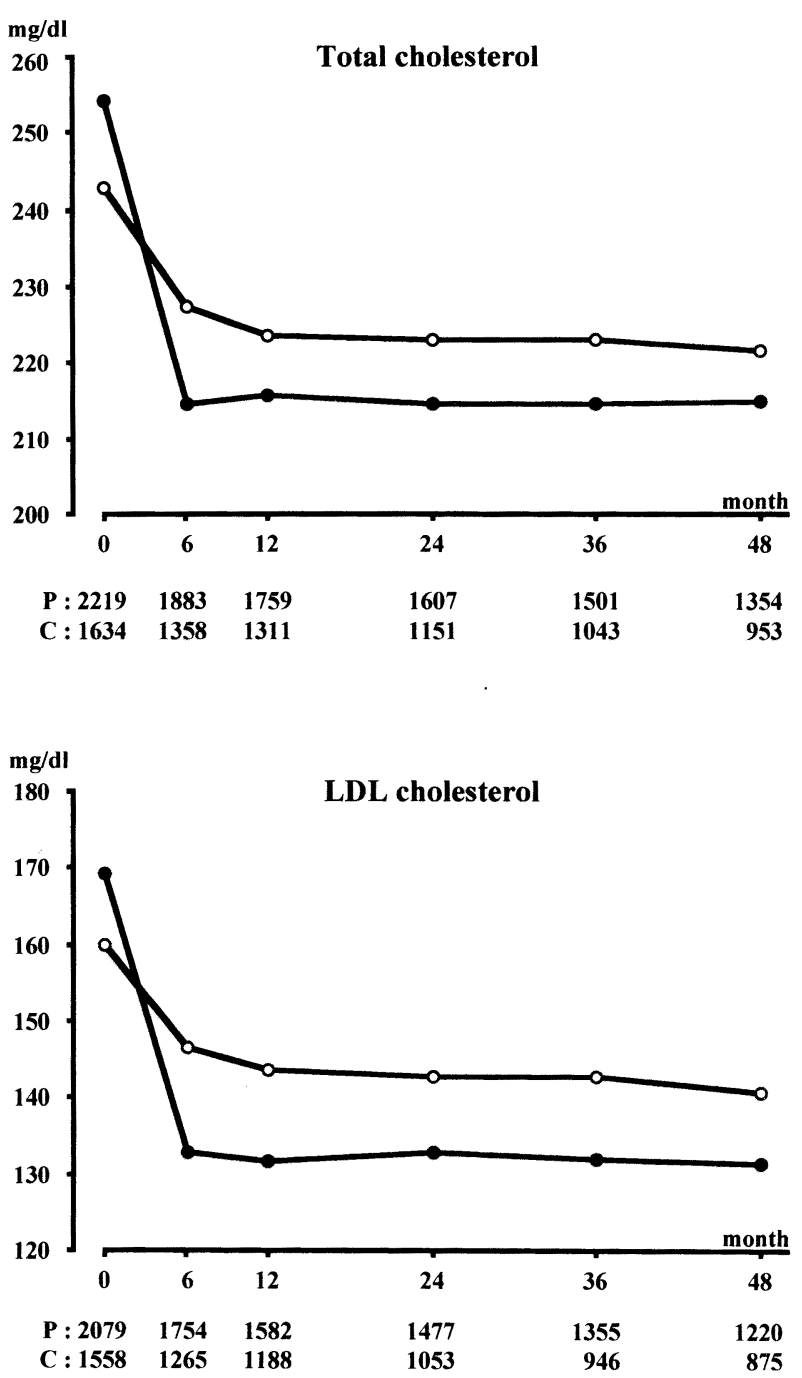

Fig. 1. Serum lipid profiles in the course of treatment in the pravastatin group (closed circle) and conventional treatment group (open circle). Numbers of patients are shown under the horizontal line. $\mathrm{P}=$ pravastatin ; $\mathrm{C}=$ conventional treatment. treatment group. Serum LDL cholesterol and triglycerides as well as body mass index were all significantly higher, and serum HDL cholesterol was significantly lower in the pravastatin group. Angina pectoris and the prior use of lipid-lowering drugs were also significantly more prevalent among men allocated to pravastatin treatment. In the contrast, diabetes mellitus, smoking, and alcohol use were slightly more prevalent among those allocated to the conventional treatment.

\section{Follow-up}

Due to delayed recruitment, nearly half of the patients did not have a time span of five years since the initiation of treatment. As of the end of 1997, 23 patients in the pravastatin group and 917 men in the control group were in the fourth year of follow-up, and 1,006 in the pravastatin group and 476 in the control group were in the fifth year. Vital status was unknown for 24 men (1.1\%) in the pravastatin group and $16(1.0 \%)$ in the control group, and the occurrence of coronary events and cerebral infarction were not ascertained for more than 3\% in each of the two treatment groups (Table 2). Person-years at risk were not constant for different endpoints because the time period after the occurrence of coronary events (or cerebral infarction) was enumerated as a period at risk for cerebral infarction (or coronary events) and death. Average years of follow-up were slightly longer in the pravastatin group (5.18 years as regards death) compared with the conventional treatment group (4.95 years).

\section{Treatment and lipid profiles}

Of men in the group of conventional treatment, 934 $(57.2 \%)$ were given non-pharmacological treatment. Numbers of men according to types of drugs in the conventional treatment group were: fibrates 253, nicotinic acid 292, and others 169; some used two or more drugs in combination. The initial dose of pravastatin was mostly $10 \mathrm{mg} /$ day. Serum lipid profiles in the course of treatment are shown in Fig. 1. An approximately $15 \%$ decrease in total cholesterol and $20 \%$ decrease in

Table 3. Numbers of events and adjusted relative risks for pravastatin use versus conventional treatment.

\begin{tabular}{|c|c|c|c|c|c|}
\hline \multirow{2}{*}{ Event } & \multicolumn{2}{|c|}{ No. of events } & \multicolumn{2}{|c|}{ Age-adjusted rate* } & \multirow{2}{*}{$\begin{array}{c}\text { adjusted RR } \\
(90 \% \mathrm{Cl})^{\dagger}\end{array}$} \\
\hline & $\mathrm{P}$ & $\mathrm{C}$ & $P$ & C & \\
\hline Coronary events & 65 & 47 & 5.77 & 5.95 & $0.86(0.61-1.20)$ \\
\hline Cerebral infarction & 47 & 41 & 4.19 & 5.15 & $0.78(0.54-1.13)$ \\
\hline $\begin{array}{l}\text { Coronary events and } \\
\text { cerebral infarction }\end{array}$ & 109 & 86 & 9.77 & 10.99 & $0.81(0.63-1.04)$ \\
\hline Total mortality & 87 & 78 & 7.58 & 9.53 & $0.79(0.60-1.04)$ \\
\hline
\end{tabular}

$\mathrm{RR}=$ relative risk $; \mathrm{Cl}=$ confidence interval $; \mathrm{P}=$ pravastatin $; \mathrm{C}=$ conventional treatment.

* Rate per 1,000 person-years. Calculated by the direct method using the person-years by 5year age class in the whole subjects as standard.

${ }^{\dagger}$ Based on the Cox hazards model controlling for age, serum total cholesterol, serum HDL cholesterol, body mass index, angina pectoris, hypertension, diabetes mellitus, prior use of lipid-lowering drugs, smoking, and alcohol use.

$\ddagger$ Coronary events and cerebral infarction combined. The earlier event was counted in the case of concurrent occurrences. 
Table 4. Mortality from selected causes in the pravastatin and conventional treatment groups.

\begin{tabular}{|c|c|c|c|c|c|}
\hline \multirow{2}{*}{ Cause of death } & \multicolumn{2}{|c|}{ No. of deaths } & \multicolumn{2}{|c|}{ Age-adjusted rate* } & \multirow{2}{*}{$\begin{array}{c}\text { Adjusted RR } \\
(95 \% \mathrm{Cl})^{\dagger}\end{array}$} \\
\hline & $\mathrm{P}$ & $\mathrm{C}$ & $P$ & $\mathrm{C}$ & \\
\hline Cancer & 30 & 28 & 2.61 & 3.41 & $0.81(0.47-1.39)$ \\
\hline $\begin{array}{l}\text { CAD and } \\
\text { cerebral infarction }\end{array}$ & 25 & 21 & 2.19 & 2.56 & $0.78(0.43-1.45)$ \\
\hline External causes & 7 & 10 & 0.60 & 1.22 & $0.40(0.14-1.11)$ \\
\hline Other causes & 25 & 19 & 2.18 & 2.34 & $0.98(0.51-1.86)$ \\
\hline \multicolumn{6}{|c|}{$\begin{array}{l}\mathrm{RR}=\text { relative risk ; } \mathrm{Cl}=\text { confidence interval ; } \mathrm{P}=\text { pravastatin ; } \mathrm{C}=\text { conventional treatment. } \\
{ }^{*} \text { Rate per } 1,000 \text { person-years. Calculated by the direct method using the person-years by } 5- \\
\text { year age class in the whole subjects as standard. } \\
{ }^{\dagger} \text { Based on the Cox hazards model controlling for age, serum total cholesterol, serum } \mathrm{HDL} \\
\text { cholesterol, body mass index, angina pectoris, hypertension, diabetes mellitus, prior use of } \\
\text { lipid-lowering drugs, smoking, and alcohol use. } \\
{ }^{\ddagger} \text { Coronary events and cerebral infarction combined. }\end{array}$} \\
\hline
\end{tabular}

LDL cholesterol were sustained from 6 months to 4 years in the pravastatin group. The percent decreases in the control group were less than half of those in the pravastatin group in the early periods, and were slightly, but progressively, accentuated with advancing time in followup. On average, the conventional treatment resulted in a $8 \%$ decrease in total cholesterol and an 10\% decrease in LDL cholesterol. Mean levels of serum total cholesterol averaged over 6-48 months in follow-up were $215 \mathrm{mg} / \mathrm{dl}$ in the pravastatin group and $224 \mathrm{mg} / \mathrm{dl}$ in the conventional treatment group (4\% lower in the pravastatin group). The corresponding values for LDL cholesterol were 132 $\mathrm{mg} / \mathrm{dl}$ and $143 \mathrm{mg} / \mathrm{dl}$, respectively $(8 \%$ lower in the pravastatin group). $\mathrm{HDL}$ cholesterol and triglycerides also showed a slightly more favorable change in the pravastatin group (data not shown).

\section{Endpoints}

Table 3 presents the results as regards the primary and secondary endpoints. After adjustment for the covariates, the risk of coronary events was $14 \%$ lower in the pravastatin group than in the conventional treatment group, but the reduction was not statistically significant $(p=0.23)$. The numbers of fatal myocardial infarction, nonfatal myocardial infarction, coronary angioplasty, coronary bypass surgery, cardiac death, and sudden death in the pravastatin group were $4,36,10,4,4$, and 7 , respectively. The corresponding numbers in the conventional treatment group were $4,20,12,3,2$, and 6 , respectively. A $22 \%$ decrease in the risk of cerebral infarction was associated with pravastatin use; again; the decrease was not statistically significant again $(p=0.13)$. Cases of suspected cerebral infarction numbered 4 in the pravastatin group and 5 in the control group. A total of 5 men developed both coronary events and cerebral infarction; 3 men in the pravastatin group developed cerebral infarction subsequent to coronary events, and 2 men in the control group had coronary events after cerebral infarction. When coronary events and cerebral infarction were combined, the risk of the composite outcome was $19 \%$ lower in the pravastatin group, and the decrease just fell short of the significance level $(p=0.08)$. Total mortality was also lower in the pravastatin group $(p=0.08)$.

Due to the lowered total mortality in the pravastatin group, selected cause-specific mortalities were compared between the two groups (Table 4); in the analysis, the two sided test was used because the direction of each association was not a prioi anticipated except for mortality from CAD and cerebral infarction. The pravastatin group showed modestly decreased mortalities not only from CAD and cerebral infarction but also from cancer and more profoundly decreased mortality from external causes; mortality from the other causes combined showed no difference between the two groups. Of deaths from external causes, accidental and suicidal deaths numbered 3 and 4 , respectively, in the pravastatin group, and 8 and 2 , respectively, in the conventional treatment group.

\section{Cancer and cerebral hemorrhage}

There were 77 and 55 incidences of cancer in the pravastatin and control groups, respectively. Nonmelanoma skin cancer was not counted. After adjustment for age (5-year class), baseline total cholesterol, angina pectoris, hypertension, diabetes mellitus, smoking, and alcohol use, relative risk for pravastatin versus control was 1.00 (two-sided 95\% Cl 0.70-1.44). Cerebral hemorrhages (including subarachnoid hemorrhage) numbered 10 in the pravastatin group and 9 in the conventional treatment group; the adjusted relative risk was 0.72 (twosided $95 \% \mathrm{Cl}$ 0.28-1.87).

\section{Compliance-based analysis}

When the pravastatin group was divided into two subgroups of poor and good compliance, the latter group showed a greater reduction in total and LDL cholesterol levels (Fig. 2). Both total and LDL cholesterol levels in the poor-compliance subgroup approached the levels in the conventional treatment group in later points at the follow-up. On average over 6-48 months in treatment, 

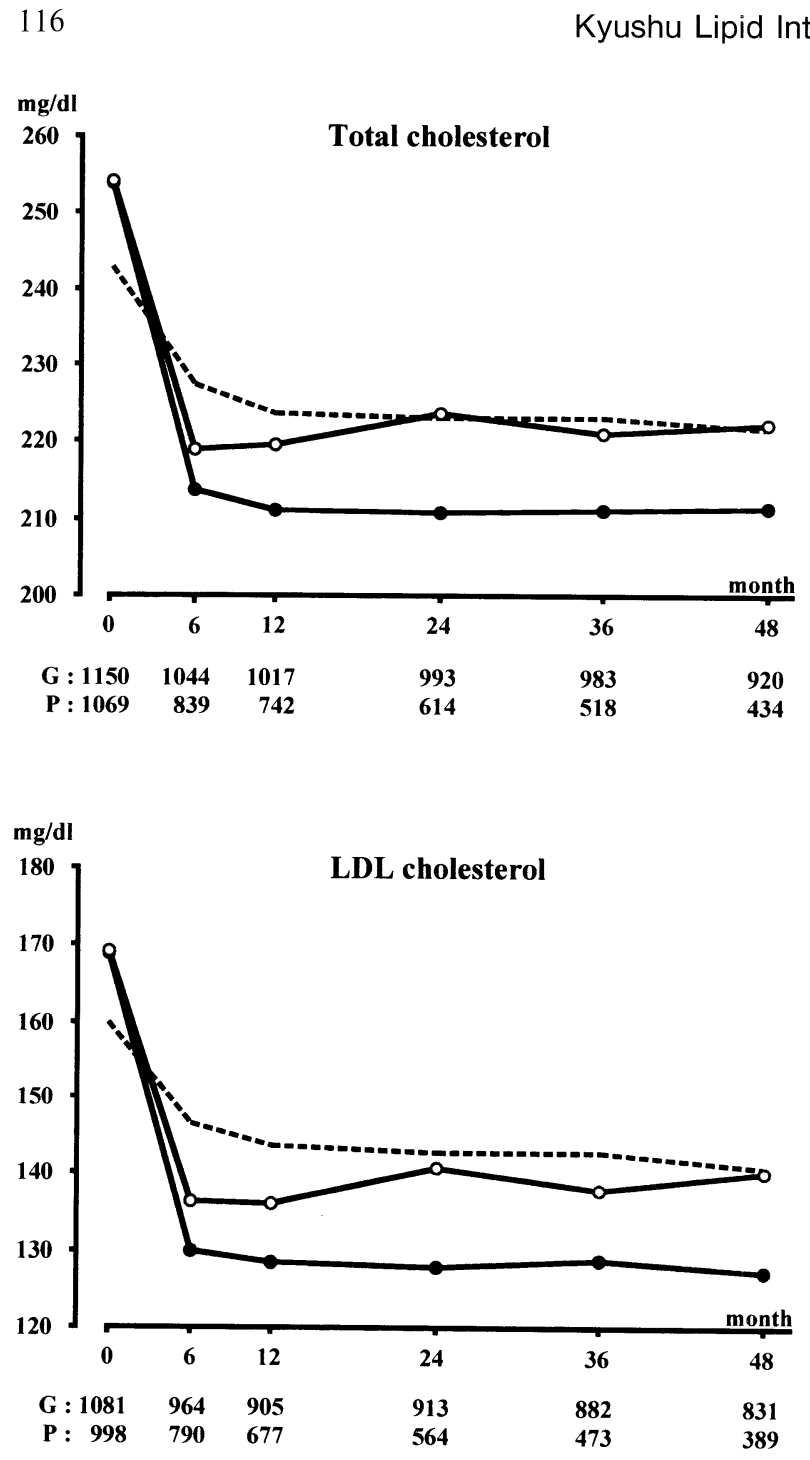

Fig. 2. Serum lipid profiles in the course of treatment for patients with a good compliance (closed circle) and those with a poor compliance (open circle) in the pravastatin group and in the conventional treatment group (broken line). Numbers of patients are shown under the horizontal line. $\mathrm{G}=$ good compliance ; $\mathrm{P}=$ poor compliance.

serum total cholesterol levels were $212 \mathrm{mg} / \mathrm{dl}$ in the goodcompliance group and $221 \mathrm{mg} / \mathrm{dl}$ in the poor-compliance group; the mean LDL cholesterol levels in the two subgroups were $128 \mathrm{mg} / \mathrm{dl}$ and $138 \mathrm{mg} / \mathrm{dl}$, respectively. As compared with the conventional treatment group, the good-compliance group had a $5 \%$ lower level of total cholesterol and a 10\% lower level of LDL cholesterol.

The good-compliance subgroup showed a more evident decrease in the risk of coronary events, cerebral infarction, and the two outcomes combined (Table 5). A decreased risk of the composite outcome of coronary events and cerebral infarction combined in the good-compliance subgroup was statistically significant $(p=0.04)$.
Table 5. Numbers of events and adjusted relative risks for poor and good compliance to pravastatin as compared with the conventional treatment.

\begin{tabular}{|c|c|c|}
\hline Event & $\begin{array}{l}\text { Poor complianc } \\
\quad(n=1,114)\end{array}$ & $\begin{array}{l}\text { od compliance } \\
(n=1,105)\end{array}$ \\
\hline \multicolumn{3}{|l|}{ Coronary events } \\
\hline No. of events & 33 & 32 \\
\hline Adjusted RR* & 1.00 & 0.75 \\
\hline$(90 \% \mathrm{Cl})$ & $(0.68-1.48)$ & $(0.50-1.11)$ \\
\hline \multicolumn{3}{|l|}{ Cerebral infarction } \\
\hline No. of events & 20 & 27 \\
\hline Adjusted RR & 0.83 & 0.74 \\
\hline$(90 \% \mathrm{Cl})$ & (0.52-1.33) & $(0.48-1.14)$ \\
\hline $\begin{array}{l}\text { Coronary events and } \\
\text { cerebral infarction }\end{array}$ & 52 & 57 \\
\hline $\begin{array}{l}\text { No. of events } \\
\text { Adjusted RR } \\
(90 \% \mathrm{Cl})\end{array}$ & $\begin{array}{c}0.92 \\
(0.68-1.25)\end{array}$ & $\begin{array}{c}0.73 \\
(0.54-0.98)\end{array}$ \\
\hline
\end{tabular}

$\mathrm{RR}=$ relative rink $; \mathrm{Cl}=$ confidence interval.

*Based on the Cox hazards model controlling for age, serum total cholesterol, serum HDL cholesterol, body mass index, angina pectoris, hypertension, diabetes mellitus, prior use of lipid-lowering drugs, smoking, and alcohol use.

${ }^{\dagger}$ The earlier event was counted in the case of concurrent occurrences.

\section{Discussion}

There were several factors which caused difficulties in completing the study as originally designed. The most serious problem was that randomization was not successful. Openness of the study as regards treatment resulted in another problem that statins were used frequently in the conventional treatment group. Although study physicians had been given a full explanation regarding randomization and the use of lipid-lowering drugs, they were not reluctant to neglect the predetermined rules because they had been well informed of the potent effect of pravastatin on serum lipids. Further, because of the introduction of a new regulation for clinical trials in the course of the study, a large number of patients had to be excluded from the study. Although the present results should be interpreted with much caution, there were several unique aspects which deserve mention. The KLIS used the conventional treatment for hypercholesterolemia in the control group, and the results are more relevant to clinical practice. A dose of $10-20 \mathrm{mg} /$ day of pravastatin was used while 40 $\mathrm{mg} /$ day was used in most of the previous trials in Western populations $(17-19,31)$. It should also be noted that cerebral infarction, not stroke collectively, was a predetermined endpoint in the present study.

Serum total and LDL cholesterol levels fell by $15 \%$ and $20 \%$, respectively, in the pravastatin group. Although these decreases were less than reported in clinical trials using $40 \mathrm{mg} /$ day of pravastatin (17-19), the observed effect of pravastatin on serum lipids and lipoproteins are in agreement with previous observations in Japan (13). 
However, the decrease in total cholesterol in the control group was larger than initially expected. Total and LDL cholesterol in the control group were progressively lower at later points in time during the observation period. Consequently, differences in total and LDL cholesterol during the follow-up period between the pravastatin and conventional treatment group were relatively small, causing difficulty in detecting protective effects of pravastatin on the primary and secondary events. Patients with a good compliance to pravastatin treatment showed much greater decreases in total and LDL cholesterol, but the differences between patients adhering to pravastatin treatment and those in the conventional treatment remained still smaller than observed in placebo-controlled trials. Although adjustment was made for known coronary risk factors, the statistical adjustment did not sufficiently control for the baseline difference in the risk resulted from non-random allocation. Taken together, the present study necessarily underestimated the true effect of pravastatin on coronary events and cerebral infarction.

The risk of coronary events was $15 \%$ lower in the pravastatin group as compared with the conventional treatment group. A good compliance with pravastatin treatment was associated with a $25 \%$ decrease in the risk of coronary events. Although part of the decreased risk may have been ascribed to a general, nonspecific effect of more attentive medical care among patients having adhered to pravastatin treatment, the decreased risk associated with a good compliance with pravastatin is not materially at variance with the reduction in coronary events or CAD-related mortality observed in placebocontrolled trials in Western populations.

In the pooled analysis of four randomized studies investigating atherosclerosis regression among moderately hypercholesterolemic patients with $\mathrm{CHD}$ (32), a $62 \%$ reduction in myocardial infarction was attributable to pravastatin use. A $42 \%$ reduction in coronary deaths was ascribed to simvastatin use in the Scandinavian Simvastatin Survival Study (20). In the Cholesterol and Recurrent Events (CARE) study (18) and the Long-Term Intervention with Pravastatin in Ischemic Disease (LIPID) study (19), pravastatin use reduced the recurrence of myocardial infarction or fatal coronary events by $24 \%$ each. In the West of Scotland Coronary Prevention Study (WOSCOPS) (17), a $31 \%$ reduction of myocardial infarction and coronary deaths combined was observed in the pravastatin group as compared with the placebo group.

Evidence is inconsistent regarding the relation between total or LDL cholesterol and the risk of stroke $(33,34)$. While earlier trials using non-statin drugs have generally failed to demonstrate a preventive effect of cholesterollowering on stroke risk (35), the LIPID (19) ad CARE (21) studies each showed a statistically significant reduction in all types of stroke combined in the treatment group. A statistically non-significant $11 \%$ reduction ascribed to pravastatin was observed in the WOSCOPS (17). In these trials, however, those with a history of stroke were not specifically excluded, and hemorrhagic stroke was not separated from cerebral infarction although the latter probably accounted for the majority of stroke cases. In the KLIS, the incidence of cerebral infarction was $22 \%$ lower in the pravastatin group and 26\% lower among those having adhered to pravastatin treatment compared with the conventional treatment group. Although the decreases were not statistically significant, the findings add to evidence that the use of pravastatin confers decreased risk of cerebral infarction.

Atherosclerosis is a common pathogenetic process for both coronary events and cerebral infarction, and it is of particular interest to examine the effect of pravastatin on the composite outcome of these two endpoints combined. Pravastatin use was associated with a $19 \%$ decrease in the risk, and compliant patients had a $27 \%$ lower risk as compared with those in the conventional treatment risk. These nearly significant and significant decreases suggest that pravastatin therapy is useful in the prevention of atherosclerotic diseases among moderately hypercholesterolemic patients.

In the present study, mortality from all causes was also decreased in the pravastatin group. Deaths from CAD and cerebral infarction accounted for less than 30\% in each of the pravastatin and conventional treatment groups each, and thus it is difficult to ascribe the lowered total mortality in the pravastatin group to the decreased risk of coronary events and cerebral infarction. Men in the pravastatin group had lower mortality not only from coronary events and cerebral infarction but also from cancer and particularly external causes although the decrease in each cause-specific mortality was not statistically significant. We have no clear explanation for the lowered mortality from cancer or external causes. The differences may be simply due to chance. It should be noted that there was no difference in mortality from the combined causes other than CAD, cerebral infarction, cancer, and external causes. It seems unlikely that the quality of medical care in the conventional treatment differed from that in the pravastatin group.

No serious adverse effect was observed in relation to the long-term use of pravastatin in the present study. Cancer incidence in the pravastatin group was almost the same as that observed in the control group. This finding corroborates previous observations regarding pravastatin use and cancer risk (17-19). It has been suspected that low cholesterol levels may be associated with increased risk of cerebral hemorrhage $(36,37)$. The present study showed no evidence that the use of pravastatin increases the risk of cerebral hemorrhage in hypercholesterolemic men. 


\section{Conclusions}

The KLIS had methodological weaknesses inherent to observational studies. Although the results need to be interpreted with caution, the overall findings add to evidence that pravastatin use is beneficial in the prevention of coronary events and cerebral infarction in hypercholesterolemic Japanese patients. The protective effect of pravastatin seems to be greater for cerebral infarction than for coronary events.

Acknowledgments: This study was supported by a research grant from Sankyo, Co. Ltd., Tokyo, Japan. The KLIS executive committee is grateful to the following physicians participating in the study: K. Abe, M. Abe, T. Abe, T. Akagaki, T. Akamine, A. Akashi, M. Akashi, S. Akazawa, T. Akiyoshi, H. Amagase, H. Amako, I. Anami, H. Anan, B. Ando, Y. Annoura, N. Aoki, T. Aoki, Y. Aoki, J. Aoyagi, M. Arakaki, O. Arasaki, K. Arikawa, T. Arima, M. Arimatsu, Y. Arita, T. Asano, K. Ashihara, N. Ashizawa, S. Atogami, H. Bekki, S. Biro, Y. Chifu, H. Chijiwa, H. Chikama, S. Daikaku, D. Deguchi, A. Doi, Y. Doi, N. Doki, T. Dozono, A. Edamitsu, S. Eguchi, K. Eishima, I. Ejima, T. Ejima, M. Endo, S. Enoki, O. Era, T. Esaki, H. Eto, H. Ezaki, T. Fujii, H. Fujimatsu, Y. Fujimoto, M. Fujino, N. Fujio, K. Fujisawa, S. Fujita, H. Fujiwara, S. Fukae, M. Fukahori, R. Fukami, S. Fukuchi, J. Fukuda, J. Fukui, S. Fukuoka, H. Fukushima, S. Fukuyama, T. Furue, K. Furukawa, T. Furukawa, T. Furuno, Y. Furusho, H. Furuzono, T. Futata, C. Goami, S. Gohara, H. Gondo, M. Gondo, I. Goto, Y. Goto, M. Gushiken, N. Gushiken, M. Gushima, M. Haji, S. Hamabe, M. Hamada, Y.Hamada, K. Hamaguchi, Y. Hamano, B. Hanamura, S. Hanashiro, K. Handa, O. Hano, H. Hara, Y. Hara, T. Harada, Y. Harada, Y. Haraguchi, K. Haramaki, K. Hashiba, A. Hashiguchi, O. Hashiguchi, T. Hashimoto, S. Hata, M. Hatanaka, N. Hattori, Y. Hattori, I. Hayaki, T. Hayashi, Y. Hayashi, K. Hayashida, T. Hayashida, R. Hazama, E. Henzan, S. Hidaka, Y. Hidaka, H. Higa, K. Higashi, M. Higashi, T. Higashi, K. Higo, I. Higuchi, N. Higuchi, S. Higuchi, M. Himeno, H. Hirai, Y. Hirai, K. Hiraiwa, T. Hiramoto, T. Hirano, H. Hiraoka, T. Hiraoka, Y. Hirase, H. Hirata, M. Hirata, T. Hirata, Y. Hiratsuji, H. Hiratsuka, S. Hiratsuka, H. Hirayama, M. Hirayama, H. Hirose, K. Hirose, T. Hirota, T. Hisadome, H. Hisayama, A. Hokao, S. Hokkoku, Y. Honda, K. Honjo, S. Honjo, H. Hori, Y. Horikawa, Y. Horikiri, K. Horiuchi, H. Hoshino, M. Hoshino, K. Hyodo, F. Ichiki, H. Ichiki, T. Ichiki, Y. Ichinose, T. Ide, M. lehara, H. Iguchi, K. lida, R. lida, K. limori, T. lino, I. liyama, T. Ijuin, K. Ikeda, T. Ikeda, Y. Ikegami, M. Ikushima, K. Ikuta, S. Ikuyama, E. Imagawa, T. Imai, S. Imamura, K. Imanishi, K. Imasato, M. Imoto, M. Inada, M. Inakura, Y. Inamori, M. Inazawa, Y. Inobe, T. Inoguchi, T. Inokuchi, J. Inoue, K. Inoue, M. Inoue, S. Inoue, T. Inoue, Y. Inoue, A. Iriki, A. Irita, T. Iseki, S. Ishida, T. Ishigami, H. Ishii, I. Ishii, K. Ishii, M. Ishii, Y. Ishii, E. Ishikawa, T. Ishikawa $S$. Ishimoto, H. Ishizaka, T. Ishizaki, T. Iteguchi, T. Ito, Y. Ito,
K. Itoman, S. Iwagawa, H. Ikakuma, T. Iwao, C. Iwasaka, K. Iwasaki, T. Iwasaki, Y. Iwasaki, K. Iwashige, M. Iwatani, K. Izumi, M. Izumi, Y. Izumi, R. Jo, J. Kabashima, J. Kagawa, M. Kagimoto, F. Kai, K. Kai, H. Kaieda, R. Kaji, Y. Kaji, S. Kajita, Y. Kajiwara, S. Kaku, T. Kaku, Y. Kaku, Y. Kamekawa, H. Kamitsuchihashi, T. Kamiyasu, T. Kamizono, H. Kamo, Y. Kamochi, K. Kan, T.Kanda, M. Kaneda, T. Kaneko, T. Kano, T. Kariya, N. Kaseda, M. Kashimura, R. Katada, T. Katayama, F. Kato, I. Katsuragi, H. Kawaguchi, S. Kawaguchi, Y. Kawaguchi, E. Kawahara, S. Kawaida, M. Kawamoto, H. Kawano, S. Kawano, K. Kawasaki, C. Kawashima H. Kawashima, M. Kawatomi, Y. Keida, H. Kido, Y. Kido, T. Kihara, A. Kiire, H. Kikuchi, M. Kikuchi, A. Kimoto, E. Kinoshita, K. Kinoshita, R. Kinoshita, S. Kinoshita, H. Kishikawa, K. Kishimoto, Y. Kitaguchi, K. Kitajima, Y. Kitano, H. Kitazaki, K. Kiue, A. Kiyonaga, K. Kiyonaga, S. Kiyota, Y. Kizaki, K. Kobayashi, R. Kobayashi, T. Kobayashi, S. Kobori, K. Koda, H. Kodama, M. Kodama, K. Kodera, T. Kodera, H. Koga, M. Koga, T. Koga, Y. Koga, M. Kohara, H. Koito, H. Kojima, N. Kojima, S. Kojima, Y. Kojima, M. Kojo, H. Komaki, Y. Komatsu, H. Komidori, A. Kondo, H. Kondo, K. Kondo, R. Konishi, M. Kono, Y. Kora, N. Koreeda, T. Kotake, S. Koyanagi, K. Kubara, M. Kubo, S. Kubo, H. Kumagae, K. Kumagae, K. Kumai, K. Kunisaki, M. Kunisaki, K. Kuramitsu, S. Kurinami, Y. Kurita, N. Kuriya, T. Kuriya, K. Kurobe, H. Kuroiwa, T. Kuroki, T. Kusaba, E. Kusano, S. Kusano, M. Kusuda, M. Kusumoto, T. Kusumoto, H. Kutsukake, K. Kuwabara, S. Kuwabara, K. Kuwahara, T. Kuwahara, Y. Kuwahara, T. Kuwahata, K. Maeda, S. Maeda, T. Maeda, Y. Maeda, Y. Magori, K. Maki, T. Maki, K. Makizumi, K. Maruoka, H. Maruta, I. Maruyama, T. Maruyama, N. Mashiko, N. Masuda, S. Masuda, T. Masuda, T. Masukawa, K. Masutomo, S. Masuzaki, H. Matsuda, M. Matsui, K. Matsumoto, M. Matsumoto, N. Matsumoto, Y. Matsumoto, A. Matsunaga, E. Matsunaga, K. Matsunaga, T. Matsunaga, E. Matsuo, H. Matsuo, S. Matsuo, T. Matsuo, Y. Matsuo, H. Matsuoka, M. Matsuoka, U. Matsuoka, K. Matsushima, I. Matsushita, T. Matsushita, T. Matsuura, K. Matsuyama, H. Matsuzaki, T. Matsuzaki, K. Mayumi, S. Miake, Y. Miike, Y. Mikagi, Y. Mikuriya, K. Mimura, E. Minagawa, O. Minami, Y. Minami, M. Mine, T. Mishima, K. Mitsugi, Y. Mitsutake, K. Mitsuyasu, K. Miura, A. Miyagawa, M. Miyagawa, H. Miyagi, T. Miyagi, T. Miyahara, C. Miyake, M. Miyamoto, Y. Miyamoto, H. Miyashita, M. Miyata, S. Miyata, K. Miyauchhi, T. Miyauchi, H. Miyazaki, K. Miyazaki, N. Miyazaki, T. Miyazaki, M. Miyazato, Y. Miyazono, A. Miyoshi, Y. Mizoguchi, O. Mizuno, M. Mizuta, K. Mochida, M. Mohri, H. Mori, I. Mori, K. Mori, T. Mori, Y. Mori, M. Morinaga, R. Morinaga, Y. Morisawa, K. Moriyama, M. Moriyama, K. Morokuma, K. Motomura, H. Motoori, H. Motoyana, Y. Mukasa, S. Mukobara, K. Murakami, T. Murakami, M. Murase, A. Murata, K. Muta, M. Muta, N. Muta, Y. Muta, K. Nagae, S. Nagafuchi, N. Nagamine, S. Nagao, T. Nagasaki, R. Nagashima, H. Nagata, K. Nagata, O. Nagata, T. 
Nagatomo, K. Naka, R. Nakagawa, T. Nakagawa, Y. Nakagawa, T. Nakajima, S. Nakama, A. Nakamura, K. Nakamura, N. Nakamura, O. Nakamura, S. Nakamura, T. Nakamura, T. Nakanishi, S. Nakano, H. Nakao, R. Nakao, T. Nakao, F. Nakashima, H. Nakashima, M. Nakashima, N. Nakanishi, S. Nakashima, S. Nakashita, K. Nakatake, Y. Nakatomi, Y. Nakaura, K. Nakayama, R. Nakayama, S. Nakayama, H. Nakazono, H. Namikawa, S. Nashiro, Y. Nasu, S. Natori, K. Niizoe, H. Ninomiya, K. Nishi, K. Nishigami, K. Nishihara, S. Nishihara, S. Nishihata, K. Nishijima, H. Nishimura, H. Nishitani, M. Nishiwaki, K. Nishiyama, M. Nishiyama, B. Noda, K. Noda, M. Noda, S. Noda, Y. Noda, H. Nodomi, R. Nomiyama, K. Nomoto, H. Nonaka, T. Nozuhara, T. Nunohiro, H. Oba, K. Obase, H. Obata, I. Oda, H. Oe, N. Oe, M. Oga, S. Ogaki, N. Ogasawara, T. Ogata, R. Ogushi, S. Oishi, H. Oka, N. Oka, R. Oka, T. Okajima, O. Okamoto, S. Okamura, T. Oketa, S. Oki, K. Okita, N. Okita, Y. Oku, M. Okubo, T. Okubo, S. Okuno, H. Okura, K. Omi, F. Omori, I. Omura, K. Onaka, H. Oniki, K. Oniki, H. Ono, N. Ono, T. Ono, Y. Ono, K. Onomura, K. Orihara, Y. Orita, M. Osabe, R. Oshibuchi, T. Oshige, T. Oshikawa, F. Oshima, Y. Oshima, H. Ota, M. Ota, Y. Ota, N. Otake, T. Otonari, Y. Otsubo, I. Otsuru, S. Otsuru, I. Oyama, M. Ozaki, K. Ozono, T. Ryo, K. Ryu, K. Sada, H. Sadamoto, K. Saeki, T. Sagara, Y. Sagara, K. Saijo, T. Saikawa, H. Saishoji, H. Saito, S. Saito, T. Saito, A. Sakai, H. Sakai, K. Sakai, T. Sakai, Y. Sakai, A. Sakamoto, S. Sakamoto, Y. Sakamoto, A. Sakaue, T. Sakisaka, O. Sakiyama, Y. Sako, K. Sakumoto, K. Sakuragawa, K. Sannomiya, T. Sano, K. Sasaki, M. Sasaki, S. Sasaki, S. Sashihara, H. Sato, M. Sato, Y. Sato, M. Seki, N. Sekiguchi, Y. Senokuchi, M. Serikawa, S. Seto, K. Shibao, H. Shibata, K. Shibata, K. Shibatomi, H. Shibuya, M. Shida, T. Shido, I. Shigematsu, T. Shiizaki, I. Shimada, K. Shimada, H. Shimamoto, M. Shimizu, N. Shimohashi, N. Shimoyama, T. Shinagawa, H. Shinboku, R. Shindo, S. Shindo, K. Shinohara, Y. Shinohara, T. Shinonome, K. Shinzato, K. Shiotani, K. Shirai, A. Shiraishi, H. Shiraishi, K. Shiraishi, M. Shiraishi, Y. Shiraishi, H. Shirohara, M. Shirozu, H. Shono, T. Shono, T. So, K. Soda, H. Soeda, J. Soejima, K. Sonoda, K. Sonoki, R. Suenaga, A. Suga, H. Sugihara, H. Sugimoto, Y. Sugiyabu, T. Sumida, T. Sumii, N. Sumita, K. Suzuki, F. Suzuki, S. Suzuki, D. Tabata, H. Tabuchi, H. Taguchi, T. Taguchi, K. Taira, H. Tajima, N. Tajima, Y. Tajiri, Y. Takada, M. Takagi, T. Takahama, A. Takahara, A. Takahashi, N. Takahashi, T. Takahashi, Y. Takaki, Y. Takamiya, K. Takano, M. Takao, M. Takaoka, K. Takayama, T. Takayama, M. Takeda, N. Takeda, S. Takei, A. Takemasa, K. Takemoto, F. Takeno, I. Takeshita, Y. Takeshita, M. Taketomi, S. Takigami, H. Takino, K. Tamura, M. Tamura, H. Tanabe, T. Tanada, F. Tanaka, H. Tanaka, J. Tanaka, K. Tanaka, M. Tanaka, R. Tanaka, S. Tanaka, T. Tanaka, H. Taneda, K. Tanigawa, M. Tanigawa, T. Taniguchi, K. Tanioka, Y. Tanioka, M. Tanoue, E. Tashiro, H. Tashiro, Y. Tashiro, N. Tateishi, K. Tateshi, H. Tatsukawa, A. Tazoe, K. Tenda, H. Terazaki, S. Terukina, G.
Toda, T. Toda, S. Togami, M. Toguchi, T. Tohara, M. Tohaya, G. Tokeshi, Y. Tokumaru, S. Toma, K. Tominaga, M. Tominaga, S. Tomino, Y. Tomioka, M. Tomisato, A. Tomita, A. Tomokiyo, A. Tomonaga, H. Tomonaga, K. Tomooka, K. Toriya, Y. Toya, F. Toyota, M. Tsubahara, T. Tsuchigame, Y. Tsuchiya, M. Tsuda, T. Tsuda, Y. Tsuda, T. Tsuiki, H. Tsukagawa, T. Tsukamoto, T. Tsukimura, S. Tsumabuki, S. Tsuno, E. Tsunoda, H. Tsurugami, F. Tsuruta, M. Tsushima, M. Tsutsui, R. Tsutsui, Y. Tsuzuki, S. Uchida, H. Uchimura, T. Uchino, K. Ueda, T. Ueda, H. Ueki, K. Ueki, S. Uekihara, N. Uemura, S. Uemura, M. Ueno, H. Uenomachi, C. Ueyama, Y. Umeno, T. Umetani, Y. Urabe, T. Usa, I. Utsunomiya, S. Wada, H. Wakasugi, J. Watanabe, T. Watanabe, K. Yakabe, H. Yamada, T. Yamada, H. Yamaga, E. Yamaguchi, H. Yamaguchi, K. Yamaguchi, M. Yamaguchi, R. Yamaguchi, T. Yamaguchi, Y. Yamakawa, T. Yamakita, A. Yamamoto, H. Yamamoto, M. Yamamoto, T. Yamamoto, Y. Yamamoto, K. Yamaoka, T. Yamasa, M. Yamasaki, K. Yamashita, S. Yamashita, Y. Yamashita, S. Yamate, T. Yamauchi, K. Yanagida, M. Yanase, A. Yano, J. Yano, K. Yano, T. Yano, M. Yao, H. Yasuda, A. Yasukochi, Y. Yokogawa, A. Yokota, M. Yokota, Y. Yokota, E. Yokoyama, N. Yokoyama, T. Yokoyama, M. Yoshida, T. Yoshida, M. Yoshihara, Y. Yoshihara, H. Yoshikawa, H. Yoshimatsu, N. Yoshimatsu, $\mathrm{H}$. Yoshimori, T. Yoshimoto, M. Yoshinaga, N. Yoshinaga, Y. Yoshio, S. Yoshioka, S. Yoshitake, T. Yoshitake, and K. Yusu. The KLIS Executive Committee also acknowledges the technical support from the staff of Sankyo, Co. Ltd.

\section{References}

(1) The Pooling Project Research Group: Relationship of blood pressure, serum cholesterol, smoking habit, relative weight and ECG abnormalities to incidence of major coronary events : final report of the pooling project. J Chron Dis, 31: 201-306, 1978

(2) Stamler J, Wentworth D, Neaton JD, et al.: Is relationship between serum cholesterol and risk of premature death from coronary heart disease continuous or graded? Findings in 356,222 primary screeness of the Multiple Risk Factor Intervention Trial (MRFIT). JAMA, 256: 2823-2828, 1986

(3) Pocock SJ, Shaper AG, and Phillips AN : Concentrations of high density lipoprotein cholesterol, triglycerides, and total cholesterol in ischaemic heart disease. BMJ, 298: 998-1002, 1989

(4) Szatrowski TP, Peterson AV Jr, Shimizu Y, et al.: Serum cholesterol, other risk factors, and cardiovascular disease in a Japanese cohort. J Chron Dis, 37 : 569-584, 1984

(5) Chen Z, Peto R, Collins R, MacMahon S, Lu J, and $\mathrm{Li} \mathrm{W}$ : Serum cholesterol concentration and coronary heart disease in population with low cholesterol concentrations. BMJ, 303: 276-282, 1991

(6) A co-operative trial in the primary prevention of ischaemic heart disease using clofibrate. Report from the Committee of Principal Investigators. $\mathrm{Br}$ 
Heart J, 40: 1069-1118, 1978

(7) Lipid Research Clinics Program: The Lipid Research Clinics Coronary Primary Prevention Trial results. I. Reduction in incidence of coronary heart disease. JAMA, 251: 351-364, 1984

(8) Lipid Research Clinics Program: The Lipid Research Clinics Coronary Primary Prevention Trial results. II. The relationship of reduction in incidence of coronary heart disease to cholesterol lowering. JAMA, 251: 365-374, 1984

(9) Frick $\mathrm{MH}$, Elo O, Haapa $\mathrm{K}$, et al.: Helsinki Heart Study: primary-prevention trial with gemfibrozil in middle-aged men with dyslipidemia. Safety of treatment, changes in risk factors, and incidence of coronary heart disease. N Engl J Med, 317 : 12371245, 1987

(10) Muldoon MF, Manuck SB, and Matthews KA: Lowering cholesterol concentrations and mortality: a quantitative review of primary prevention trials. BMJ, 301: 309-314, 1990

(11) Law MR, Thompson SG, and Wald NJ: Assessing possible hazards of reducing serum cholesterol. BMJ, 308: 373-379, 1994

(12) Tsujita $Y$ and Watanabe $Y$ : Pravastatin sodium : a novel cholesterol-lowering agent that inhibits HMGCoA reductase. Cardiovasc Drug Rev, 7 : 110-126, 1989

(13) Saito Y, Goto Y, Nakaya N, et al. : Dose-dependent hypolipidemic effect of an inhibitor of HMG-CoA reductase, pravastatin (CS-514), in hypercholesterolemic subjects: a double blind test. Atherosclerosis, $72:$ 205-211, 1988

(14) Pitt B, Mancini GB, Ellis SG, Rosman HS, Park JS, and McGovern ME : Pravastatin limitation of atherosclerosis in the coronary arteries (PLAC I) : reduction in atherosclerosis progression and clinical events. PLAC I investigation. J Am Coll Cardiol, 26: 11133-1139, 1995

(15) Byington RP, Furberg CD, Crouse JR 3rd, Espeland $M A$, and Bond MG : Pravastatin, Lipids, and Atherosclerosis in the Carotid Arteries (PLAC-II). Am J Cardiol, 76 : 54C-59C, 1995

(16) de Groot E, Jukema JW, van Boven AJ, et al.: Effect of pravastatin on progression and regression of coronary atherosclerosis and vessel wall changes in carotid and femoral arteries: a report from the Regression Growth Evaluation Statin Study. Am J Cardiol, 76 : 40C-46C, 1995

(17) Shepherd J, Cobbe SM, Ford I, et al.: Prevention of coronary heart disease with pravastatin in men with hypercholesterolemia. West of Scotland Coronary Prevention Study Group. N Engl J Med, 333 : 13011307, 1995

(18) Sacks FM, Pfeffer MA, Moye LA, et al.: The effect of pravastatin on coronary events after myocardial infarction in patients with average cholesterol levels. Cholesterol and Recurrent Events Trial investigators. N Engl J Med, 335: 1001-1009, 1996

(19) The Long-Term Intervention with Pravastatin in Ischaemic Disease (LIPID) Study Group: Prevention of cardiovascular events and death with pravastin in patients with coronary heart disease and a broad range of initial cholesterol levels. $\mathrm{N}$ Engl J Med,
$339:$ 1349-1357, 1998

(20) Scandinavian Simvastatin Survival Study Group: Randomised trial of cholesterol lowering in 4444 patients with coronary heart disease: the Scandinavian Simvastatin Survival Study (4S). Lancet, 344: 1383-1389, 1994

(21) Plehn JF, Davis BR, Sacks FM, et al. : Reduction of stroke incidence after myocardial infarction with pravastatin: the Cholesterol and Recurrent Events (CARE) study. Circulation, 99: 216-223, 1999

(22) Uemura $\mathrm{K}$ and Pisa $\mathrm{Z}$ : Trends in cardiovascular disease mortality in industrialized countries since 1950. World Health Stat Quart, 41 : 155-178, 1988

(23) Shimamoto $\mathrm{T}$, Komachi $\mathrm{Y}$, Inada $\mathrm{H}$, et al.: Trends for coronary heart disease and stroke and their risk factors in Japan. Circulation, 79: 503-515, 1989

(24) Tamura A, Mikuriya $Y$, and Nasu M: Effect of pravastatin $(10 \mathrm{mg} /$ day) on progression of coronary atherosclerosis in patients with serum total cholesterol levels from 160 to $220 \mathrm{mg} / \mathrm{dl}$ and angiographically documented coronary artery disease. Coronary Artery Regression Study (CARS) Group. Am J Cardiol, 79: 893-896, 1997

(25) Sacks FM, Pfeffer MA, Moye L, et al.: Rationale and design of a secondary prevention trial of lowering normal plasma cholesterol levels after acute myocardial infarction: the Cholesterol and Recurrent Events trial (CARE). Am J Cardiol, 68: 14361446, 1991

(26) The West of Scotland Coronary Prevention Study Group: A coronary primary prevention study of Scottish men aged 45-64 years: trial design. J Clin Epidemiol, 45 : 849-860, 1992

(27) The Kyushu Lipid Intervention Study Group: A coronary primary intervention study of Japanese men: study design, implementation and baseline data. J Atheroscler Thromb, 3: 95-104, 1996

(28) Halperin M, Rogot E, Gurian J, and Ederer F : Sample size for medical trials with special reference to long-term therapy. J Chron Dis, 21: 12-24, 1968

(29) Conference concensus: J Jpn Atheroscler Soc, 15 : 1109-1148, 1987

(30) Friedewald WJ, Levy RI, and Fredrichson DS : Estimation of the concentration of low-density lipoprotein cholesterol in plasma without use of the preparative ultracentrifuge. Clin Chem, 18: 459502, 1972

(31) The Lipid Research Clinics Program : The coronary primary prevention trial : design and implementation. J Chron Dis, 32 : 609-631, 1979

(32) Byington RP, Jukema JW, Salonen JT, et al.: Reduction in cardiovascular events during pravastatin therapy. Pooled analysis of clinical events of the Pravastatin Atherosclerosis Intervention Program. Circulation, 92: 2419-2425, 1995

(33) Benfante R, Yano K, Hwang LJ, Curb JD, Kagan A, and Ross W: Elevated serum cholesterol is a risk factor for both coronary heart disease and thromboembolic stroke in Hawaiian Japanese men. Implications of shared risk. Stroke, 25: 814-820, 1994

(34) Prospective Studies Collaboration: Cholesterol, diastolic blood pressure, and stroke : 13,000 strokes 
in 450,000 people in 45 prospective cohrorts. Prospective studies collaboration. Lancet, 346 : 1647-1653, 1995

(35) Atkins D, Psaty BM, Koepsell TD, Longstreth WT Jr, and Larson EB : Cholesterol reducction and the risk for stroke in men. A meta-analysis of randomized, controlled trials. Ann Intern Med, 119: 136-145, 1993

(36) Tanaka $\mathrm{H}$, Ueda $\mathrm{Y}$, Hayashi $\mathrm{M}$, et al.: Risk factors for cerebral hemorrhage and cerebral infarction in a Japanese rural community. Stroke, 13:62-73, 1982

(37) Yano K, Reed DM, and MacLean CJ: Serum cholesterol and hemorrhagic stroke in the Honolulu Heart Program. Stroke, 20:1460-1465, 1989

\section{Appendix}

Executive Committee : Kikuo Arakawa (principal investigator), Jun Sasaki (head of the trial office), Kei-ichi Araki (deceased, head of data management office), Fukuoka University; Motosuke Hanada, Karatsu Red Cross Hospital ; Yasushi Ishihara, Ishihara Hospital for Cardiovascular Diseases; Hajime Nawata, Kyushu University; Masato Ageta, Miyazaki Nichinan Prefectural Hospital ; Takehiko Fujino, Kyushu University ; Hisashi Kanaya, Kanaya Cardiovascular Clinic ; Shunichi Koga, lizuka Hospital; Shiro Mawatari, Fukuoka Women's University; Takashi Yanagawa (statistical adviser), Suminori Kono (trial adviser), Kyushu University. The committee is in charge of writing scientific papers.
Endpoint and Adverse Effect Committee: Masato Ageta; Takashi Asano, Fukuoka University; Takehiko Fujino; Hisashi Kanaya; Shunichi Koga; Shiro Mawatari.

Local Organizers : Fukuoka Prefecture: Mitsuo Fujino, Yoshihiko Ikeda, Hiromu Kawashima, Keiichi Midorikawa, Shigetada Ninomiya, Kazuyuki Saeki, Masayuki Shimokobe, Sakutaro Takano, Yoichi Tanabe, Fumio Umeda, Yasushi Yokota; Saga Prefecture: Hideo Ikeda, Tadahiro Mizukami, Toshiaki Sunaga (deceased), Kyosuke Yamamoto; Oita Prefecture: Kanichiro Akioka, Toshio Goto, Ichiro Hata, Hideto Higashi, Sukenobu Ito, Jin Iwao, Shunichi Kodama, Masaru Miyake, Nobuya Nagamatsu, Yasuhiro Oribe, Yoshimi Oshima, Toshiie Sakata, Masashi Seita, Susumu Shimada, Yoshihisa Shimazu, Masaaki Tokieda, Kohei Yamaguchi ; Nagasaki Prefecture: Toshiyuki Imamura (deceased), Jiro Kubo, Yoshiyuki Miyahara, Fumiya Murakami, Katsusuke Yano; Kumamoto Prefecture: Shoji Fukumitsu, Takashi Honda, Satoru Horita, Tomio Jinnouchi, Keizo Kajiwara, Takafumi Odo, Motoaki Shichiri; Miyazaki Prefecture: Takeo Ayabe, Sumito Kariya, Yasuhide Soda, Hiroshi Urakami ; Kagoshima Prefecture: Seiji Nishi, Hiromitsu Tanaka, Takashi Tsuchimochi.

External Review Committee: Yuichiro Goto (Chairman), Tokai University, Japan ; lan Ford, Glasgow University, UK; Yuji Matsuzawa, Osaka University, Japan; Kazuo Ueda, Kyushu University, Japan; and Takesumi Yoshimura, University of Occupational and Environmental Health Sciences, Japan. 